\title{
Predicting the relationships between virtual enterprises and agility in supply chains
}

\author{
Ariunbayar Samdantsoodol ${ }^{\mathrm{a}}$, Shuang Cang ${ }^{\mathrm{b} *}$, Hongnian $\mathrm{Yu}^{\mathrm{c}}{ }^{\text {, }}$, Alan Eardley ${ }^{\mathrm{a}}$, Asralt Buyantsogt ${ }^{\mathrm{d}}$
}

${ }^{\mathrm{a}}$ Faculty of Computing, Engineering and Sciences, Staffordshire University, Stafford, ST18 0AD, UK

E-mail address: A.Samdantsoodol@staffs.ac.uk (Ariunbayar Samdantsoodol); W.A.Eardley@staffs.ac.uk (Alan Eardley)

${ }^{\mathrm{b}}$ Faculty of Management, Bournemouth University, Poole, BH12 5BB, UK

${ }^{*}$ Corresponding author E-mail address: scang@bournemouth.ac.uk (Shuang Cang)

${ }^{c}$ Faculty of Science and Technology, Bournemouth University, Poole, BH12 5BB, UK

E-mail address: yuh@bournemouth.ac.uk (Hongnian Yu)

${ }^{\mathrm{d}}$ Department of Logistics and Transportation Management, Mongolian University of Science and Technology,

Ulaanbaatar, Mongolia

E-mail address: asralt@must.edu.mn (Asralt Buyantsogt) 
Predicting the relationships between virtual enterprises and agility in supply chains

\section{ABSTRACT}

In the recent advanced information communications and technology (ICT) era, collaborating virtually and temporarily in supply chains (SCs) to receive mutual benefits such as agility while sharing resources and information becomes an important strategy for enterprises that seek to increase their competitiveness and to optimise their processes and resource usage. As a dynamic and temporary form of alliance from the resource perspective, virtual enterprises (VEs) may contribute network resource heterogeneity and sustain competitive advantage. In addition, agility is suggested as a rare, valuable, network resource that is difficult to imitate and that cannot easily be substituted by other attributes.

Although many researchers have investigated VEs and their agility, the research pays less attention to the relationship between VEs and agility in complex SC situations. This paper therefore investigates the relationship between VE and agility in SCs (ASCs) and explores drivers and enablers of agility and outcomes. A conceptual hypothetical model is proposed that demonstrates the relationship between the significant factors. To clarify the relationships between these factors a structural equation model (SEM) is adopted to examine the model fit according to the measurement variables and supporting hypotheses. The results provide rich empirical evidence of the beneficial impact of VEs on ASCs, and theoretical and managerial insights that can be used to strengthen the drivers, enablers and capabilities to enhance the effectiveness of VE collaboration in ASCs in a global and dynamic context.

Keywords: Virtual enterprises; Agility in supply chains; Resource-based view; Higher-order factor analysis; Structural Equation Model

\section{Introduction}

While the external environment influences organisations, it is becoming more difficult and expensive for one company to handle all these issues and to adapt in a competitive context. Therefore, many companies are paying more attention on collaboration and investing in more flexible logistics processes and supply chain (SC) networks supported by information communications and technology (ICT). Hence, collaborative behaviour and activities in SC management (SCM) have gained considerable importance as an essential precondition of staying competitive and enhancing performance, which in turn intensifies the efforts to build enhanced value-based relationships through the SC (Koçoğlu et al., 2011). Kumar and Nath (2014) indicate that collaboration is a core strategy for developing competitive advantages in SC. However, SC partners benefit from collaboration may tend to collaborate in the long-term to seek higher performance gains, and successful collaboration in SC leads to a long-term partnership for the collaborating enterprises (Ramanathan and Gunasekaran, 2014).

The emerging collaborative and integrated business strategy are geared towards maximising the benefits of the relatively narrow windows of opportunity yielded by increasingly volatile global markets, and by optimally sharing the resources and profits through forms of collaboration. Recently, development of strategies for competing on the agility basis has become the strategic management basis of the total SC. Ismail and Sharifi (2006) define agility as the SC ability to rapidly align the network and its operations to meet the dynamic and turbulent requirements of the individual members. Even where agility is a winning strategy for enterprises, the idea of creating agile capability becomes a logical step for companies. Christopher (2000) indicates that to be truly agile, a SC must possess a number of distinct characteristics including market 
sensitive, virtual, network-based and process-integrated. Researchers often assume that the dynamic collaborative form of a VE is an agility enabler (Cruz-Cunha and Putnik, 2006).

A VE is a temporary alliance of enterprises that come together to share core competencies and resources to better respond to business opportunities, and whose co-operation is supported by ICT (Camarinha-Matos et al. 2009). Aerts et al. (2002) conclude that to cope with the momentary unavailability of a particular type of capability a VE includes several members with similar capabilities (i.e. redundancy) to help them to achieve agility. The agility capability shows how well the collaboration is defined and how the processes provide business and technological integration between enterprises within the SC. Furthermore, SC agility affects an enterprise business performance (BP) significantly (DeGroote and Marx, 2013).

However, this paper argues that some studies investigate only the empirical evidence of the drivers, enablers and capabilities of agility (Ngai et al., 2011; Liu et al., 2013) while others explore only the relationship between VE and ICT and the effects on BP (Cao and Dowlatshahi, 2005). There is a consequent lack of evidence empirically proving how a strategy of joining in VE influences agility in SC (ASC) and consequently BP. Thus, the paper aims to identify and analyse the relationship between drivers, enablers, capability and outcomes of competitive strategy forming VE to achieve ASC, and to provide practitioners and researchers with critical insights into the relationship between the factors. With reference to the resource-based view (RBV), this study discusses the theoretical background and develops a novel conceptual model for the relationship between VE and ASC. The hypotheses about the relationship between factors are investigated through a literature review and are tested by a higher-order factor analysis. The paper is organised as follows: section 2 provides an overview of collaboration in SC, VE and ASC from a RBV perspective. Hypotheses are developed based on the literature review and a conceptual model is proposed in Section 3. In Section 4, an empirical study is conducted with several stages of analysis and discussions are followed. Conclusions, limitations and suggestions for future research are given in Section 5.

\section{Literature review}

The RBV is adopted as a major theoretical background for understanding the relation between VE formation and agility in SC collaboration (SCC). To develop a competitive advantage for firms, the RBV relies on an organisation's competitive strategy and the creation of value primarily by applying tangible or intangible resources that have the four attributes of value, rarity, inimitability and non-substitutability. According to Barney (1991), firms achieve a competitive advantage when implementing a value creating strategy that is not simultaneously implemented by any current or potential competitors. When other firms are unable to duplicate the benefits of the strategy, competitive advantage is sustained. The traditional RBV is based only on singular or 'focal' firms, but Lavie (2006) extends the RBV by integrating a relational view with social network theories, and identifies four specific 'rents' or benefits that partners could receive from an interconnected alliance. The four rents of the competitive advantage of a local firm participating in an alliance/collaboration include: 1) internal rent, 2) appropriated relational rent, 3) inbound spill-over rent, and 4) outbound spill-over rent. In this view internal rent is extracted from the shared and non-shared resources of its alliance partners. Dyer and Singh (1998) envisage firms receiving relational rent as a supernormal profit 
that can only be created through the joint contributions of the collaborative partners by combining and exchanging relation-specific assets, knowledge-sharing routines, complementary resources and capabilities and effective governance. Lavie (2006) determines the proportion of relational rents that are appropriated by the firm. Firms accumulate inbound spill-over rent through knowledge transfer, inter-firm learning, their relative absorptive capacity, and the internalisation of the partner's practices. However, sometime a loss of outbound spill-over rent may result from the transfer of benefits from the focal firm to the partner.

To win the advantage determined by Lavie (2006) in the networking field, the modern competitive scenario pushes firms to explore new inter-firm organisational relationship models in two complementary directions: firstly, flexibility; and secondly, the intensive use of ICT to manage information and knowledge to exploit innovation and collaborative relationships in a more efficient and effective way (Esposito and Evangelista, 2014). In recent environments co-ordination and co-operation between competitors and partners (rather than the optimisation of individual functions within a single organisation) would add to the competitive success of modern SCs (Wang et al., 2007). Thus the focus of SCM has shifted from the competitive advantage of individuals to the competitive advantage of the entire SC. Nowadays, the organizational structure of the VE is indicated as a suitable dynamic co-ordination and co-operation model for addressing changing market conditions through flexibility, and extensive ICT usage based on the core competency of partners (Esposito and Evangelista, 2014). Compared with traditional alliances, VE is a more dynamic and temporary structure that relies on multi-period formulation rather than on a single phase of interaction to exploit fast changing business opportunities in the market (Lavie, 2006). The VE main objective is to allow several organizations to develop a common working environment rapidly; and hence to manage a collection of resources provided by the participating organizations toward the attainment of some common goals (Gunasekaran et al., 2008).

Barney (1991) identifies resource heterogeneity and imperfect mobility as important sources of competitive advantage for firms. The strategic resources controlled by a firm may be heterogeneous, and as these strategic resources may not be perfectly duplicated in each partner firm and that condition establishes heterogeneity for long lasting. However Lavie (2006) views the heterogeneity condition as being tied to the conceptualization of firms as independent entities, and the affiliation of alliances may contribute to resource homogeneity by facilitating asset flows among interconnected firms. This paper argues that as a temporary alliance the formation of a VE establishes network resource heterogeneity and therefore imperfect mobility. The formation of each VE has its unique pathway through the creation and dissolution stages, and it could be an informal single-shot and autonomous strategy by itself and would not be easily duplicated by other networked alliances simultaneously in a short time period, affording competitive advantage to the partners. The complexity of members and their resources in a short period of time contributes VE resource heterogeneity and imperfect mobility. For instance, closely knit, highly experienced VE management teams are rare because they are socially complex and may be imperfectly imitable (Barney, 1991). Also, VE formation could enable simultaneous rent generation and appropriation at the network level (Lavie, 2006). The network resources (Gulati, 1999) are external resources embedded in the firm's alliance network that provide strategic opportunities and affect the network's behaviour and value. They include all the assets, capabilities, 
organizational processes, firm attributes, information, etc. controlled by the VE that enable the enterprise to conceive and implement strategies that improve its efficiency and effectiveness (Barney, 1991).

Agility is considered in the present context (i.e. of resources providers) as the capability of achieving rapid adaptation and reconfiguration through cooperation to response to market changes. As an ability to be tolerant of external changes, an ASC is perceived as having the capability of being competitive in a global market and having an increased chance of long-term survival and greater profit potential (Gunasekaran and Yusuf, 2002). In this study, agility is perceived as an operational capability that is valuable, rare and imperfectly imitable (Liu et al., 2013) and as a non-substitutable network resource. Firstly, capabilities of exploiting profitable opportunities in volatile business environments, responding rapidly and effectively to unanticipated opportunities and proactively developing solutions for potential needs make agility more valuable. Secondly, agility is a rare network resource because rapid and proactive adaptation in unexpected and unpredicted changes is difficult goal to achieve. Researchers agree it is not easy to find practical applications of VE that enable agility (Cruz-Cunha and Putnik, 2006; Camarinha-Matos et al., 2009). Thirdly, agility is an imperfectly imitable networked resource. VE have own way to achieve agility by exploring unanticipated changes successfully and responding it by own competitive bases (speed, flexibility, innovation proactivity, quality and profitability) through the integration of reconfigurable resources and best practices in a knowledge-rich environment. Finally, all above conditions make agility non-substitutable. In recent years, evidence has accumulated suggesting that resources of alliance partners transferred via direct inter firm interactions have a considerable impact on firm performance (Lavie, 2006). Ngai et al. (2011) view RBV as providing a robust framework for analyzing the relationship between SC competence and firm performance, and thus propose that $\mathrm{SC}$ agility is positively associated with firm performance.

As a strategy to achieve agility, a VE needs to be created based on a VE Breeding Environment (VBE) (Camarinha-Matos et al., 2009). A VBE defined in this paper is an association of organizations and their related supporting institutions, adhering to a long-term cooperation agreement, and adopting common operating principles and infrastructures, with the main goal of increasing both their chances and preparedness for collaboration in potential VE. The VBE can be a network of enterprises within SC that provides base level of trust by previous collaboration and enables selecting partners for VE from the range of available enterprises. RBV of the firm also receives much attention in explaining SCC. Lavie (2006) states horizontal alliances among competitors that collaborate strategically able to receive inbound spill-over rent from shared or non-shared firm resources. Dyer and Singh (1998) view collaborative partners accrue the relational rent as a common benefit, and joint competitive advantage from it composes a collaborative advantage. The relational rents are created gradually, as a consequence of continuous collaboration (Lavie, 2006), but cannot be generated individually by a collaborative partner (Cao and Zhang, 2011).

This paper proposes an aggregated schema based on RBV (Figure 1) through which the benefits of collaboration, the success of a value-creating strategy based on previously conducted collaboration and the efficiency and effectiveness of network resources might be measured by a change in BP. The aggregated main research domain includes (i) SCC as a long term partnership, (ii) VE as a strategy that is conducted based on 
collaboration and that copes with network resource heterogeneity and immobility, (iii) agility as a capability and a rare, valuable and imperfectly imitable network resource that is enabled and improved by a proper strategy, and (iv) BP as a measure of effectiveness of strategy and network resource usage.

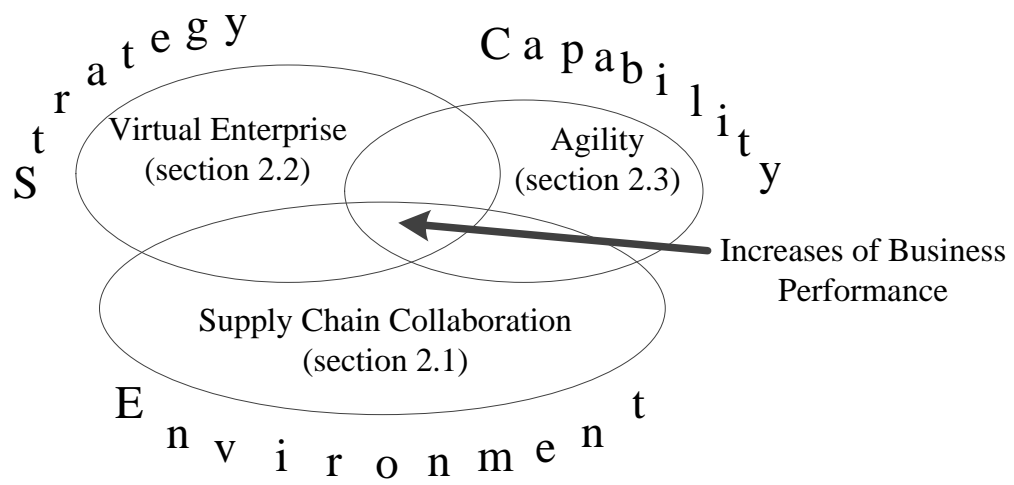

Figure 1: Proposed aggregated domain schema

\subsection{Supply Chain Collaboration}

Since the mid-1990s, collaboration within SC has received attention from academics and practitioners (Liao and Kuo, 2014). SCC is described as an inter-organisational relationship type where the partners agree to invest resources, mutually achieve goals, share information, rewards and responsibilities as well as jointly make decisions and solve problems (Soosay et al., 2008). SCC is recognised a main tool for enterprises to achieve better performance and benefits and develop advantages with partners rather than single firm. The papers (Kumar and Nath, 2014; Ramanathan and Gunasekaran, 2014) highlight many SCC benefits that include the decreasing costs, lead time and inventory levels, and increasing of service levels, profit, flexibility, end-customer satisfaction and product quality while dealing with high demand uncertainties.

To accrue these benefits, several SC collaborative practices (Vendor Managed Inventory, Efficient Consumer Response, Collaborative Forecasting Planning and Replenishment, Continuous Replenishment, and Electronic Data Interchange) are reported and accepted that creating a seamless, synchronized SC leads to increased responsiveness and lower inventory costs (Liao and Kuo, 2014). For example, Hewlett-Packard, IBM, Dell, Procter and Gamble have forged long-term, collaborative relationships with their suppliers to reduce transaction costs and achieve a stronger competitive position (Ramanathan and Gunasekaran, 2014). Rodríguez and Vilana (2010) analyse the practice of Rolls Royce based on three vectors: the globalization of internal processes; the supply and value chains of all the centres involved; and strategic alliances with companies outside the organization. They conclude the collaboration network is based on greater 'virtualization', and it is becoming more common and efficient at meeting the market requirements, to reduce risk and access new market and seamlessly incorporate. Cao and Zhang (2011) view firms are looking outside their organizational boundaries for opportunities to collaborate with SC partners to ensure efficiency and responsiveness of SC, so as to leverage the resources and knowledge of their suppliers and customers in the past decade.

Recently, rapid ICT development supports SCC by sharing large amounts of information quickly to develop and implement coordinated responses to market changes in a timely, accurate, and cost effective 
manner (DeGroote and Marx, 2013). It opens the door to geographically distributed enterprises to collaborate and integrate virtually and coordinate their activities effectively and efficiently across the SC to response to market requirements. Since trust is always a key issue in sharing the information knowledge virtually, collaborative partner selection and the related trust issues such as trust evaluation, mutual trust, and trust building largely affect the success of a virtual collaboration (Camarinha-Matos et al., 2009). Long terms SCC establishes the base trust for organizations to more dynamic collaboration, reduces the cost/time to find suitable partners for configuration of the dynamic collaboration, provides some commonality for interaction by offering base ICT infrastructure and cooperative business rules for flexible collaboration.

\subsection{Virtual enterprise in supply chain management}

Since the concept of VE emerged in late 1980s, researchers distinguish VE from a mere collaboration and integration of business entities in outsourcing, and see VE as technology-driven dynamic alliances formed based on the sharing of information systems (ISs) (Esposito and Evangelista, 2014). Initially, a VE is defined as a virtual corporation that refers to a number of independent vendors, customers, even competitors, composing a temporary network organisation through IT, to share the technology and cost and to meet the market demand (Davidow and Malone, 1993). An evolving corporate model is fluid and flexible, implying a group of collaborators that quickly unite to exploit a specific opportunity and may dissolve equally and quickly if the situation changes (Byrne et al., 1993). Many researchers (Cruz-Cunha and Putnik, 2006, Camarinha-Matos et al., 2009) give a definition of VE from different fields with different perspectives, but it is still difficult to find a unique definition. Generally, it is considered for the purposes of this research that a VE has following essential characteristics that distinguish VE formation from traditional alliance:

- Virtuality. It usually highly relies on ICT. Utilization of ICT enables geographically dispersed enterprises to join in VE to keep their time and cost to achieve business goal. A VE owns no inventoried resources, assets, plants, factories or warehouses itself, ICT support to coordinate members owned assets.

- Dynamics. VE is highly dynamic and may have short life cycles. The temporary structure can be formulated again with same or different partners, multi periodically, to exploit new coming business opportunities in the market.

- Flexibility. VE has a strategic objective to maximise flexibility and adaptability to environmental changes.

- Autonomy. To design an effective enterprise collaboration, workflow and information flows need to be controlled by a well-defined knowledge management system. To respond fast changing environment and enable flexibility, an automatically negotiating and decision making system is mostly adopted for VE. Most researches rely on a multi agent system that interacts to solve problems which are beyond the individual capacities or knowledge and makes decision as quick and correct as possible in VE.

- Heterogeneity and immobility. VE is affiliated based on resource and core competencies of different firms by sharing different information, knowledge, and skills to obtain competitive advantages in a short run. New market opportunities no longer exist profitable, thus forming VE could be defined as a heterogeneity and immobility organizational process. 
VE has captured the attention of SCM and ICT engineering researchers who focus on planning, coordination, controlling systems among knowledge development and distribution using ICT to drive an "innovation explosion". VE is different from virtual manufacturing (Gunasekaran et al., 2008). VE is development of partnerships based on core competencies and the real sense of VE is formed on the bases of virtual manufacturing that uses computer simulation to model real world manufacturing processes for the purpose of analysing and understanding them. As a partnership strategy, temporary alliances facilitate agility (Gunasekaran and Yusuf, 2002).

\subsection{Agility in Supply Chain Management}

The agility concept, introduced by the Iacocca Institute (Nagal and Dove, 1991), has received considerable focus in the last two decades. Swafford et al. (2008) suggest that it enables an organisation to react quickly and effectively to marketplace volatility and other uncertainties. The Advanced Research Programs Agency and the Agility Forum define agility as, "the ability to thrive in an environment of continuous and often unanticipated change" (Sarkis, 2001).

Recently, ASC refers to a firm's ability to perform well operational activities together with channel partners to adapt or respond to marketplace changes in a rapid manner (Liu et al., 2013). Researchers conceptualize SC agility with two features: the exploration and exploitation of market opportunities; and the ability to deliver innovative products and services in a timely and cost-effective manner (Ngai et al., 2011). To explore market opportunities, tight collaboration with partners and communication with customers (Braunscheidel and Suresh, 2009) are perceived basis of ASC. To provide ability to be responsive, flexible and quick, the adoption of ICT ( DeGroote and Marx, 2013) and ICT based integrated organization structures (Ngai et al., 2011) have received wide attention from academics and practitioner. Rational operational strategies (Tseng and Lin, 2011; Liu et al., 2013) enable agility and make it rare, valuable, inimitable and non-substitutable.

Many models and references are suggested to conceptualize agility and measure agility capability. For instance, Agarwal et al. (2007) model agility and propose assessing features, Yauch (2011) tries to establish audit metrics of ASC by measuring some elements' changes, that can enable agility, Liu et al. (2013) study agility empirically in complex environment by connecting with drivers, enablers and outcomes of agility.

However SCC targets to reduce waste, the lean and agile paradigms can be combined within successfully designed and operated 'total SCs' and accepted to be mutually supportive (Naylor et al., 1999). Enterprises that relied more on the lean strategy win on cost and those that relied more on the agile strategy win on speed, flexibility and their responsiveness to changes (Zhang and Sharifi, 2007). When integrating these strategies, enterprise agility should be based not only on responsiveness and flexibility, but also the cost and quality of goods and services that the customers are prepared to accept (Gunasekaran and Yusuf, 2002).

\section{Conceptual models and hypotheses}

To analyse the aggregated research schema in Figure 1 empirically, a novel complex conceptual model shown in Figure 2 is proposed. The purpose is to investigate how drivers and enablers cause enterprises to join in VE and achieve in agility, how VE formation impacts on ASC based on previous partnering collaboration, and how achieved agility through strategies joining in VE causes BP. The conceptual model consists of 2 
drivers; 2 enablers; capability of ASC and the BP as an outcome, that are investigated through a literature review and hypothesized the relation among them. Drivers lead to practical tools that are enablers to provide capability with better outcomes.

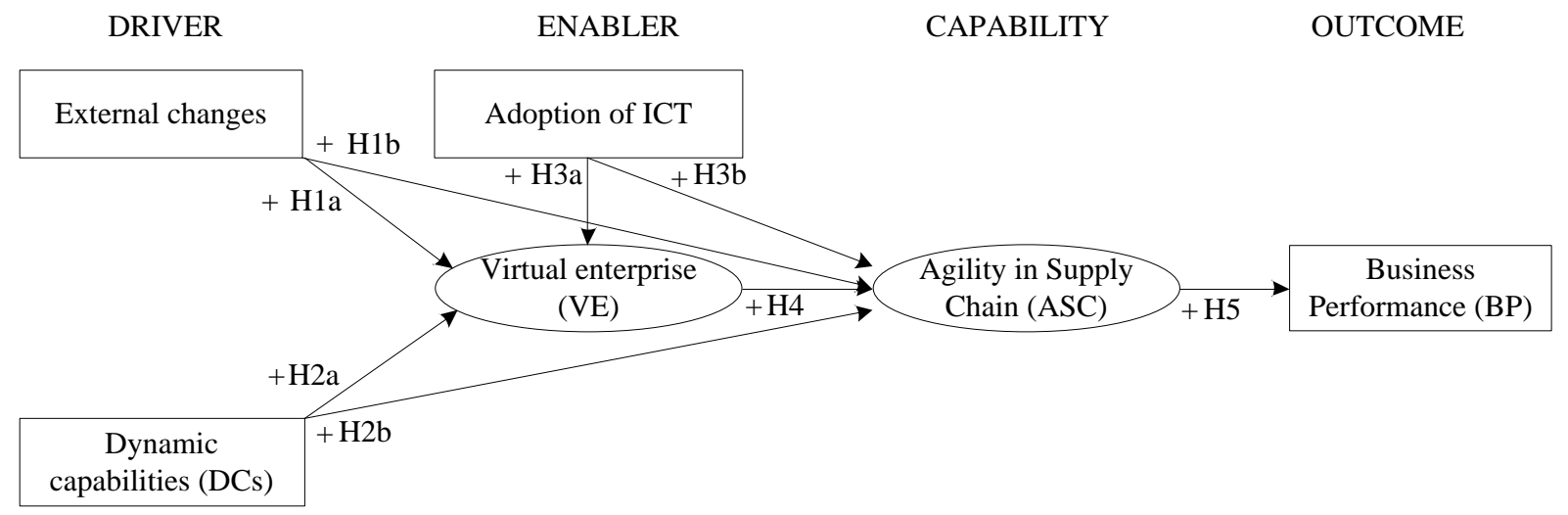

Figure 2: Proposed conceptual model

(The hypotheses H1a, H1b, H2a, H2b, H3a, H3b, H4 and H5 will be presented below)

\subsection{Drivers}

Drivers lead a company to embrace a suitable strategy to maintain competitive advantage. In the context of firm strategy, drivers are the essential driving forces for the firm to rethink about its strategy (Zhang and Sharifi 2007). Two types of drivers investigated in this work are: 1) external changes (drivers) which enterprises cannot affect but to which they need to adapt; and 2) internal drivers (resources owned by enterprises, including dynamic capabilities (DCs)) which are changeable and manageable by the organisation itself and support the company in achieving a specific performance through the chosen strategy. Both drivers push enterprises to increase BP by achieving agility through their VE forming strategy.

Yusuf et al. (2004) view unprecedented pressures of competition from foreign products, new product introduction by competitors, falling product life cycles, unanticipated customer shifts, and advances in manufacturing and ICT on companies push companies to improve their operational efficiency for enhancing competitiveness and overall BP. Researchers define such as environment as a set of external contextual elements that represent a source of opportunities and threats (Vázquez-Bustelo et al., 2007). This changing context drives organizational changes and leads to collaborate temporary through joining in VE (Katzy et al., 2004), to turn that changes into business opportunities or adapt in that changes. The VE model is indicated as suitable for addressing changing market conditions (Esposito and Evangelista, 2014) while firms collaborate strategically internalize the resources of their alliance partners to cope with turbulence and uncertainty in the business environment. Camarinha-Matos et al. (2009) classify VE into grasping opportunity driven collaborative network. Thus, to exploit fast-changing opportunities, and accrue inbound spill-over rent that is associated with strategic collaboration (Lavie, 2006), the ideal type of VEs is implemented as a certain short term project with potential members.

Agility reflects a comprehensive response to the business challenges of profiting from rapidly changing, continually fragmenting markets for high performance, high quality, customer configured goods/services 
(Zhang and Sharifi, 2007). They determine firm various changes in the business environment which drive it to prioritise "agility capabilities" that need to be developed to cope with and take advantage of changes. Competing firms having the characteristic of relatively unpredictable changes in the environment must develop higher levels of agility to be successful (Vázquez-Bustelo et al., 2007).

However few researches address how external changes affect the choice of VE strategy to achieve agility, and drive ASC. External driving forces can bury a business if they are not appropriately dealt with. For a business to succeed and to gain a competitive edge, the enterprises involved must assess the external driving forces and know what changes are indeed occurring, and what changes might be coming up in the future. Therefore, external change is chosen as one factor affecting both VE and ASC and their relationship for the proposed conceptual model. The hypotheses are proposed: H1a: External changes positively lead to VE formation. H1b: External changes positively drive ASC.

Teece et al. (1997) define DCs as the firm's ability to integrate, build, and reconfigure internal and external competences to address rapidly changing environments. Dynamically renewing the distinctive abilities of competency makes network resource heterogeneous, inimitable and rare. DCs reflect organization's ability to achieve innovative forms of competitive advantage given path dependencies and market positions (LeonardBarton, 1992). Although Binder and Clegg (2007) view core competencies and outsourcing as the main drivers of VE and Cao and Dowlatshahi (2005) view core competency to be one of the aligning items of VE to achieve improved BP, this study envisages the core competency in a dynamic pattern. VE should be formed based on the DCs that renew competences to respond to shifts by exploiting existing internal and external capabilities.

Kidd (1994) views agility as being achieved through the integration of the internal capacities of human resources and ICTs. Gunasekaran and Yusuf (2002) state agility must be supported by flexible people, processes and technologies to effect changes in firms, structure and organization with an objective being competitive. Vázquez-Bustelo et al. (2007) view human resource, technologies, practices relating to internal organisation and external relations, to product development and to knowledge management and learning are enablers of agility. This paper argues these firm resources are fundamental condition to provide ASC, thus includes it into the driving factor. Unfortunately, there is little evidence investigated into the impact of DCs on both VE and agility, and on achieving agility through VE strategy in the research domain. The H2a and H2b are also hypothesised: H2a: DCs positively drive VE formation. H2b: DCs positively provide ASC.

\subsection{Enablers}

Enablers are leveraging tools for a company to improve its capabilities. Agility enablers consist of strategies and technologies that relied on collaboration and ICT adoption. Such enablers are clearly a key to the acceleration of information flow between enterprises to leverage collaboration in SC. Many researchers (Cao and Dowlatshahi, 2005, Camarinha-Matos et al., 2009, Esposito and Evangelista, 2014) agree that ICT and strategy based on ICT like VE affiliation are a key for effective and efficient SC by speeding up the information flow, shortening the response time to customer needs, providing enhanced coordination and collaboration and sharing the risks as well as the benefits. Koçoğlu et al. (2011) investigate how information 
sharing significantly contributes to reduce SC costs, to improve partnerships, to increase material flow, to enable faster delivery and to improve order fulfilment rate, thus to contribute to increased customer satisfaction, enhanced channel coordination, and the achievement of competitive advantage.

ICT infrastructures play the intermediary role as the enabler of inter-operation among organisations and the support services provided and involved in the VE (Camarinha-Matos et al., 2009). It is the basic enabler of safe and co-ordinated interactions among the VE members. The fast development of ICT is therefore another empowering factor for VE to enable processing large amount of data and save time.

ICT is also regarded as a major enabler and facilitator of agility. Top management should actively engage in a strategic ICT plan for SC agility and for measuring its effect on SC performance (Ngai et al., 2011). Liu et al. (2013) propose a model to examine how IT capabilities (i.e., flexible IT infrastructure and IT assimilation) affect firm performance through absorptive capacity and SC agility and empirically validate the hypotheses. DeGroote and Marx (2013) conduct empiric survey that investigates the impact of IT on SC agility measured by the ability to sense and respond to market changes, and the impact ASC on firm performance.

Although some researches have been conducted on the effects of ICT on VE (Cao and Dowlatshahi, 2005) and ASC (Swafford et al., 2008; Liu et al., 2013), there are still insufficient empirical studies of the influences of ICT on the relationship between VE strategy and agility capability. The proposed hypotheses are: H3a: ICT positively enables VE. H3b: ICT positively leverages ASC.

VE is one of agility enablers. Gunasekaran and Yusuf (2002) define the VE formation tools/metrics as one of seven key agility enablers and state it is essential to develop VE in a more productive way by reducing the time and cost as well as delivering goods/services in a competitive manner in global markets. Van Hoek et al. (2001) identify virtual integration that relates to leveraging information, as one of five dimensions which reflect the more general aspects of ASC. Agility is achieved through the integration of enterprises, that is called virtual corporation, based on core competence with highly skilled and knowledgeable employees, advanced technologies and intelligent decision making systems (Kidd, 1994). Agility means using market knowledge and a virtual corporation to exploit profitable opportunities in a volatile marketplace (Naylor et al., 1999). However, empirical studies of how the VE enables the agility that affects BP are rare in the literature. Thus the following hypothesis is offered to investigate the VE impact on agility in a complex system with other factors affecting and influencing BP: H4: VE positively enables the ASC.

\subsection{Capabilities}

SC agility is referred as a type of operational capability (Liu et al., 2013) that reflects a high-level routine or a collection of routines that are used to respond to market changes. The DCs determined as an internal driver in this study is distinguished from operational capability and regarded as a higher-level routine that is used to adapt operational routines and capabilities to develop new value-creating strategies. Christopher (2000) defines agility as a business-wide capability that embraces organisational structures, ISs, logistics processes and mindsets. Gunasekaran and Yusuf (2002) state that agility is the organization capability, by proactively establishing virtual manufacturing with an efficient product development system, to meet the changing market requirements, maximise customer service levels and minimise the cost of goods. Enterprises 
prioritise the agility capabilities that need to be developed to cope with and take advantage of changes (Zhang and Sharifi, 2007). Tseng and Lin (2011) view SC agility capabilities depend on the effects of drivers and enablers.

Ngai et al. (2011) explore the impact of the relationship between SC competence and agility on firm performance. DeGroote and Marx (2013) empirically test ASC impact on performance in complex situation with different factor influences. However, no evidence is found on how BP has been impacted by a strategy of joining in VE for providing ASC. Therefore we offer the following hypothesis: H5: SC agility positively influences BP.

Many researchers perceive that it is possible to measure capabilities by performance outcomes (Tseng and Lin, 2011; Yauch, 2011). The outcome of strategy is measured by its effect on BP in this study. The effect is conceived as a change in BP (Cao and Dowlatshahi, 2005; Swafford et al., 2008; Liu et al., 2013).

\section{Empirical study}

The proposed hypothetical conceptual model in Figure 2 was tested by the empirical study based on the questionnaire. The survey was targeted at logistics companies who are responsible for planning, coordinating, control, realising and monitoring of all internal and network-wide material and product flow, with the necessary information flow, in industrial and trading sectors along the complete value-added chain for the purpose of conforming to customer requirements in Ulaanbaatar (Mongolian city). From the members list of Mongolian Logistics Association, companies have a direct export and import with abroad companies for last three years ${ }^{1}$ were selected as a target group. Mongolia is indicated as one of the 'Global Growth Generators' (i.e. countries with the most promising growth prospects for 2010-2050) (Business Insider 2011). Recently, mining sector rises as a major industry and a number of foreign firms have started mining businesses in Mongolia. Following these increases, massive mining projects are implemented with foreign investment, which opens collaboration virtually and temporary to achieve business purpose within governmental contract and many other business sectors are blooming consequently.

Web services emerge as a serious technology to provide the middleware platform to support effectively operations of a VE (Rezgui, 2007) that enable alliances to be agile with quick response with which it can respond to changing market requirements (Gunasekaran and Yusuf, 2002). These criteria indicate companies are interested in collaborating with potential partners. This research uses the methodology with three steps (Hair et al. 2010) to find the causal relationship in Figure 2,: 1) exploratory factor analysis (EFA) is adopted to identify underlying constructs by eliminating variables with weak or negative correlations; 2) confirmatory factor analysis (CFA) is conducted to measure the model fit based on the result of prior exploratory analysis; 3) path analysis of the structural equational model (SEM) is used to test hypotheses,.

\subsection{Data collection}

The questionnaire consists of three sections. Section 1 contains basic questions of profile information of participating enterprises. The position of respondents is defined to give confidence that participants have the

\footnotetext{
${ }^{1}$ Data collected from statistics of Mongolian Customs on the web page of http://www.customs.gov.mn
} 
capability and experience to answer the questions. Section 2 provides questions on drivers, enablers and capabilities which cause on relationship between VE and ASC. Section 3 covers questions related to the success of ASC. Questions are ranked with a five point Likert scale (very low rate to very high rate) to reduce skewing of the statistical problem.

Hard and soft copies of questionnaires were conveniently distributed to the selected companies. Participants were treated as autonomous agents by informing them about the study and allowing them to voluntarily choose to participate or not. Pilot study of five draft questionnaires with the cover letters were submitted to a focus group of two academics and three practitioners, to check the readability and possible ambiguity of the questionnaire and four of them replied. The interviews were conducted with respondents and minor changes were made such as rewording some questions, removing several unnecessary items and simplifying the language. In the $1^{\text {st }}$ round 400 questionnaires were distributed and 179 responses were received. In the $2^{\text {nd }}$ round, another 100 were distributed and 54 were returned. Out of 233 responses, 205 were usable. The other 28 unusable responses did not contain sufficient data for further analysis. Although this response rate $(41 \%)$ is not unusual it is recognised that 205 responses cannot cover the total business firms in the whole market.

The non-response bias (Armstrong and Overton, 1977) was tested by comparing the chi-squares of overall assessments of key factors of the responses from the single-mailing respondents, and the respondents of hard copy of questionnaire. No significant differences were found between these two groups and the result indicated that non-response bias was not serious in this study. The responses of company profiles are shown in the Table 1 which is a wide variety of industry type that identified from the Mongolian Statistical Yearbook.

Table 1: Company profile

\begin{tabular}{|c|c|c|c|c|c|}
\hline Type of industry ${ }^{a}$ & Frequency & Percentage & Number of employees ${ }^{b}$ & Frequency & Percentage \\
\hline Transport and Freight Forwarder & 37 & 18.05 & $1-9$ & 48 & 23.41 \\
\hline Mining and Quarrying & 29 & 14.15 & $10-19$ & 49 & 23.90 \\
\hline Construction and Materials & 23 & 11.22 & $20-49$ & 33 & 16.10 \\
\hline Wholesale and Retail trade & 20 & 9.76 & $50-199$ & 31 & 15.12 \\
\hline Other services & 17 & 8.29 & over 200 & 44 & 21.46 \\
\hline Hotels and Restaurants & 15 & 7.32 & Company annual & Frequency & Percentage \\
\hline Information and Communication & 13 & 6.34 & turnover & & \\
\hline Tourism & 5 & 2.44 & (tugrug-Mongolian & & \\
\hline Oils and Gas & 2 & 0.98 & currency) $)^{b}$ & & \\
\hline Manufacturing/ Processing & & & Less than 250 million & 72 & 35.12 \\
\hline Food products and Beverages & 13 & 6.34 & Less than 1 billion & 61 & 29.76 \\
\hline Apparel and Textile & 10 & 4.88 & Less than 1.5 billion & 19 & 9.27 \\
\hline Wood and Wooden products & 6 & 2.93 & More than 1.5 billion & 53 & 25.85 \\
\hline $\begin{array}{l}\text { Publishing, Printing and Reproduction of } \\
\text { recorded media }\end{array}$ & $\begin{array}{l}6 \\
5\end{array}$ & $\begin{array}{l}2.93 \\
2.44\end{array}$ & $\begin{array}{l}\text { Designation } \quad \text { of } \\
\text { respondents }\end{array}$ & Frequency & Percentage \\
\hline $\begin{array}{l}\text { Parmaceuticals, Medical products and } \\
\text { Biotechnology } \\
\text { Paper and Paper products }\end{array}$ & 4 & 1.95 & $\begin{array}{l}\text { CEO, Director } \\
\text { Manager }\end{array}$ & $\begin{array}{l}78 \\
117\end{array}$ & $\begin{array}{l}38.05 \\
57.07\end{array}$ \\
\hline
\end{tabular}




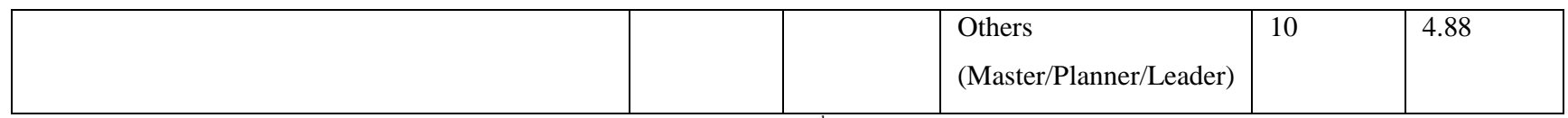

Type of industry was defined based on Mongolian Statistical Yearbook $2010 ;{ }^{\mathrm{b}}$ Classification of enterprises regarding to the Mongolian Law on Small and Medium Enterprises

\subsection{Identification underlying factors}

EFA is used as a variable reduction technique that identifies the number of latent variables (constructs) and the underlying structure of a set of variables, estimates latent variables which influence responses on observed variables. Principle component analysis (PCA) was applied for factor extraction. The constructs were rotated using varimax rotation to maximize the variance of the squared loadings of a construct on all the variables in a matrix, which has the effect of differentiating the original variables by the extracted constructs. Some variables without strong correlations are eliminated from the data set. Hair et al. (2010) suggest the variable elimination criteria consists of (a) factor loading equal or above 0.50; (b) eigenvalues greater than 1.0; and (c) results of the PCA explaining usually $60 \%$ or higher of total variance, these criteria are used in the EFA.

EFA using SPSS (IBM Corporation, 2011) was performed based on the importance rating of the constructs in six main factors, separately. The results of the EFA are shown in Appendix A. The Kaiser-Meyer-Olkin (KMO) measure (Kaiser, 1974) of sampling adequacy is obtained from EFA. The result shows great KMO values (greater than 0.8 ) and indicates that components of factor analysis are acceptable.

To test the reliability of internal consistency of constructs during EFA, the Cronbach's alpha (CA) coefficient was used. A commonly accepted rule of thumb for the scale of CA is above 0.7 (Kline, 2011). CAs are calculated for all constructs and ranges from 0.674 to 0.945 , which indicates acceptable internal consistency (Appendix A). However, the construct CA of the changes in customer requirements (0.674) is slightly below the threshold. Although this low CA could pose a problem, it is included in the establishment of factors for the hypothetical model, as it is an important characteristic in the research.

\subsection{Assessing of the measurement model}

In this section CFA was performed to test whether the data fits the hypothesised measurement model and the measures of a latent variable are consistent with the nature of observed variable. The SPSS ${ }^{\circledR}$ AMOS (Arbuckle, 2013) was used to calculate the formation of the causal relationship among the concepts that comprise the hypothetical model, and to analyse the level of influence among the causal relationships. A consensus among the following fit indices is sought and compared with threshold suggested by Hair et al. (2010). Absolute fit indices measure how well the model is specified by the observed data. That includes chi square and degree of freedom $\left(\chi^{2}: \mathrm{df}\right)$ ratios on the order of 3:1, SRMR (standardized root-mean-square residual) below 0.09, and RMSEA (root-mean-square-error of approximation) below 0.08. Incremental fit indices measure how well the estimated model fits relative to some alternative baseline model. Commonly accepted rule of thumb for the CFI (competitive fit index), incremental fit indices of IFI (incremental fit indices), NFI (normed fit index), and NNFI (non-normed fit index) are above 0.9 (Hair et al., 2010).

In this study the measurement model was developed with five $2^{\text {nd }}$-order factors and one $1^{\text {st }}$-order factor consist of items resulted from EFA, that are loaded above 0.6 and were extracted in related constructs within 
related factors. To assess whether all $1^{\text {st }}$-order constructs reflected the $2^{\text {nd }}$-order factors, the $2^{\text {nd }}$-order CFA was conducted for five $2^{\text {nd }}$-order factors by using extracted $1^{\text {st }}$-order constructs. As the results of Table 2 indicates that all higher-order measurement models have an acceptance fit.

\begin{tabular}{cccccccccc}
\multicolumn{10}{c}{ Table 2: Fit indices of measurement model } \\
\hline Fit indices & $\chi^{2}$ & Df & $\chi^{2} / \mathrm{df}$ & SRMS & RMSEA & CFI & IFI & NFI & NNFI \\
\hline Threshold & & & $<3$ & $<0.09$ & $<0.08$ & $>0.90$ & $>0.90$ & $>0.90$ & $>0.90$ \\
\hline External change & 65.624 & 40 & 1.641 & 0.051 & 0.056 & 0.965 & 0.965 & 0.916 & 0.951 \\
DCs & 208.706 & 92 & 2.269 & 0.047 & 0.079 & 0.949 & 0.950 & 0.913 & 0.934 \\
ICT adoption & 192.333 & 104 & 1.849 & 0.087 & 0.065 & 0.965 & 0.966 & 0.928 & 0.954 \\
VE & 321.518 & 204 & 1.576 & 0.051 & 0.053 & 0.961 & 0.962 & 0.902 & 0.952 \\
ASC & 219.880 & 125 & 1.759 & 0.043 & 0.061 & 0.970 & 0.970 & 0.934 & 0.954 \\
\hline
\end{tabular}

\subsection{Hypotheses testing}

In the hypothesis testing, a result is statistically significant if p-value (Fisher, 1970) is less than the predetermined significance level which is often 0.05. SEM is applied and the path coefficient measures the power of effect from causal variable to an endogenous variable. SEM is used to identify the underlying structure, for example of identifying demand during promotions (Ramanathan and Muyldermans, 2011; Subramanian et al., 2014). Direct and indirect relationship (Kline, 2011) between the factors are determined and discussed. The direct effect is a directional relationship between two variables, (i.e. independent and dependent variables). The indirect effect is the effect of an independent variable on a dependent variable through one or more intervening or mediating variables. The total effect is represented by the sum of direct and indirect effect.

The values of the absolute fit indices from Figure 3 indicate an acceptable fit between the hypothetical model and the sample data. Although, the values of the incremental fit indices slightly below the suggested threshold, these values could be accepted. Hair et al. (2010) suggest no single 'magic' value always distinguish good models from the bad models, thus the $\mathrm{R}^{2}$ value should be concerned. If a minimum $\mathrm{R}^{2}$ value of 0.5 had ever been imposed, it would be just an arbitrary limit that would exclude potentially meaningful research (Hair et al., 2010). Figure 3 shows $\mathrm{R}^{2}$ for dependent variables and all range above 0.65, within acceptable range. The result of structural model indicates that the ASC is negatively influenced by the DCs and the adoption of ICT. The remaining factors all have positive influences.

All three factors including the external change (standard coefficient $r=0.361, p<0.001, t>1.96$ ), the DCs $(\mathrm{r}=0.634, \mathrm{p}<0.001, \mathrm{t}>1.96)$ and the ICT adoption $(\mathrm{r}=0.351, \mathrm{p}<0.001, \mathrm{t}>1.96)$ have positive and significant influence on VE. These three latent factors explain $65.6 \%\left(\mathrm{R}^{2}=0.656\right)$ of the total variance of the VE. In other words, the error variance of VE is approximately $34.4 \%$ of the variance of the VE itself. These results support $\mathrm{H} 1 \mathrm{a}, \mathrm{H} 2 \mathrm{a}$ and H3a hypotheses. 


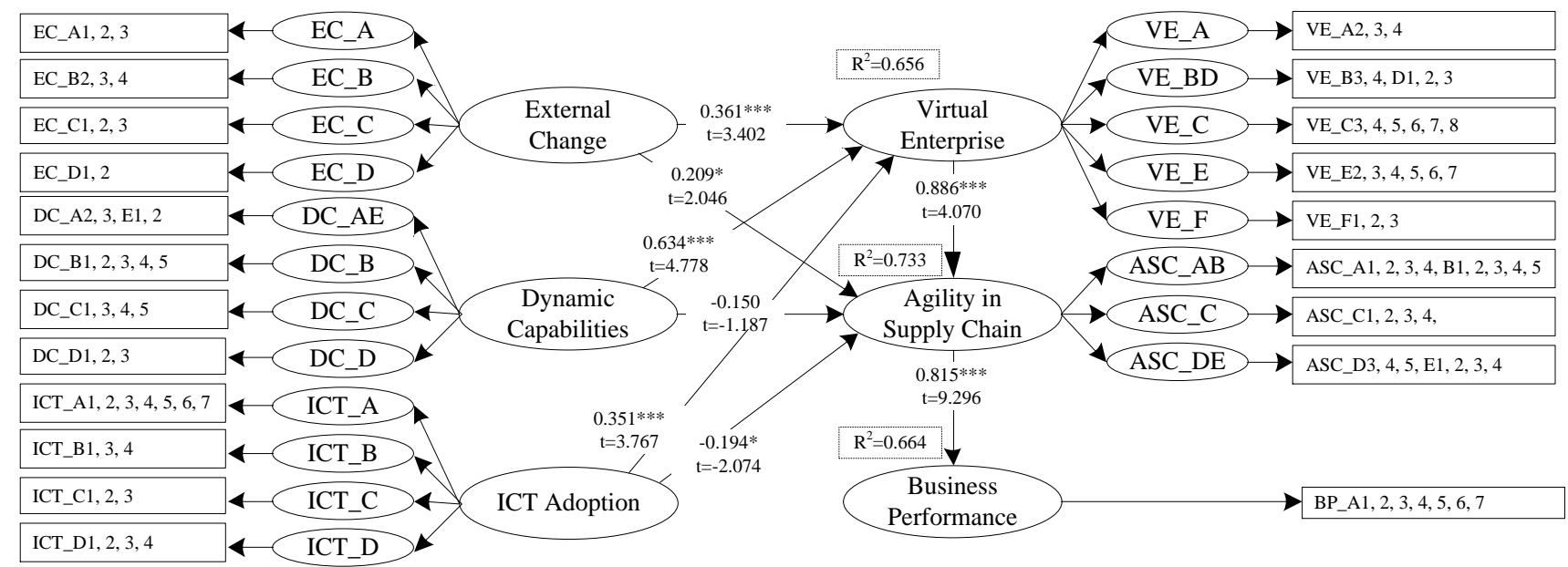

Notes: $* \mathrm{p}<0.05 ; * * \mathrm{p}<0.01 ; * * * \mathrm{p}<0.001$ Meanings of the abbreviation are presented in Appendix A

Figure 3: Structural equational model with five $2^{\text {nd }}$-order factors and one $1^{\text {st }}$-order factor

The analytical results reveal that external change $(r=0.209, \mathrm{p}<0.05)$ has significant and positive effect on the ASC. However the DCs ( $\mathrm{r}=-0.150)$ does not have a significant influence on the ASC. The ICT adoption $(r=-0.194, p<0.05)$ negatively and significantly influences the ASC. The VE $(r=0.886, p<0.001)$ has strong positive and significant effect on the ASC. These predictors explain $73.3 \%\left(\mathrm{R}^{2}=0.733\right)$ of variance of the ASC. Thus, the results support H1b, H3b, H4 but not H2b. Similarly, ASC ( $=0.815, \mathrm{p}<0.001)$ has a significant and positive influence on the BP. The t-value associated with the relationship between ASC and BP was strongest. The error variance of BP is approximately $66.4 \%\left(\mathrm{R}^{2}=0.664\right)$ of the BP variance itself. This result supports H5. Table 3 displays the relationships between these factors. Even though all three factors (external change, DCs and ICT adoption) have positive direct effects on the VE, the DCs have a stronger effect. While the VE has the strongest positive direct effect on the ASC, the ICT adoption has the strongest negative direct effect on ASC. The ASC has strong and positive direct effect on the BP.

There is no indirect effect on VE affiliation. However, three factors (external change, DCs and ICT adoption) have a positive indirect effect; the DCs have strongest indirect effect on the ASC. The total effect of the ICT adoption on the ASC is 0.117. This means that, in the long term, the improvement of ICT adoption provides superior achievement for the ASC more efficiently rather than in the short term. Finally, the four variables (external change, DCs, ICT adoption and VE) affect the BP positively and indirectly. The VE has the highest indirect effect on the BP. Controlling ASC causes an improvement in the BP index directly, while an improvement in VE provides indirectly a high BP for a long period.

Table 3: Direct and indirect effect

\begin{tabular}{cccccc}
\hline \multirow{2}{*}{ Endogenous variables } & \multicolumn{5}{c}{ Exogenous variables } \\
\cline { 2 - 6 } & External change & DC & ICT adoption & VE & ASC \\
\hline \multirow{2}{*}{ VE } & 0.361 & 0.634 & 0.351 & - & - \\
ASC & 0.209 & -0.150 & -0.194 & 0.886 & - \\
BP & - & - & - & - & 0.815 \\
& & - & Indirect effect eff & & - \\
VE & - & - & - & - & \\
\hline
\end{tabular}




\begin{tabular}{cccccc} 
ASC & 0.310 & 0.562 & 0.311 & & - \\
BP & 0.431 & 0.335 & 0.095 & 0.722 & - \\
& & \multicolumn{2}{c}{ Total effect } \\
VE & 0.361 & 0.634 & 0.351 & - & - \\
ASC & 0.529 & 0.411 & 0.117 & 0.886 & - \\
BP & 0.431 & 0.335 & 0.095 & 0.722 & 0.815 \\
\hline
\end{tabular}

\subsection{Discussions}

Empirical evidences in this study offer new findings on the association between drivers, enablers, capability and outcomes of VE and agility relationship in complex. It is proven that the enterprises can receive benefits when they properly perform the strategy to form the VE to achieve more responsiveness, flexibility, adaptability and quickness within turbulent environment.

Along the line of evidence for the impact of drivers and enablers on VE, this study has provided empirical evidence that external changes drive to form VE by leveraging ICT adoption and based on the DCs. The research confirms that three factors positively and significantly influence VE affiliation. First, the evidence strongly supports that the DCs have the most strong and positive influences on VE affiliation. This finding suggested the VE affiliation not only based on the core competency, but also relied on ability for renewing competencies to address rapid changes. This study extended the previous understanding that VE affiliated based on core competency (Cao and Dowlatshahi, 2005; Binder and Clegg, 2007; Camarinha-Matos et al., 2009) and provided evidence that to form more dynamic alliance, VE needs to be affiliated based on DCs of member enterprises. Second, the result confirms that ICT adoption has positive impact on forming VE. The findings consists with prior studies that proposed the notion that ICT is a main enabler of VE (Byrne et al., 1993; Cao and Dowlatshahi, 2005; Rezgui, 2007; Camarinha-Matos et al., 2009; Esposito and Evangelista, 2014). To be flexible and react quickly, part or full integration of ICT leverages VE to receive benefits from temporary alliance formation. The issues of integration of different objectives, such as agents, software, activities and systems, and interoperability and negotiations to make VE autonomous could extend this study furthermore. Third, the result also supports that external changes have positive and significant impact on VE. This finding consists with previous assertions (Katzy et al., 2004; Esposito and Evangelista, 2014) that indicate external changes drive enterprises to explore new inter-firm organisational relationship models such as VE that fits better for new conditions of the competitive scenario and to maintain competitive advantage (Byrne et al., 1993). Even so, enterprises joining in a VE need to handle environmental changes carefully to achieve better output.

Furthermore, this study also identifies the impact of drivers and enablers on the ASC. The result has proven external changes directly drive agility leveraging by VE to respond quickly to fast changing business opportunities. First, the empirical study evidenced, that the VE is the most strong and positive influencing factor on the ASC. This result confirms the statements of many researchers (Kidd, 1994; Cao and Dowlatshahi 2005; Cruz-Cunha and Putnik, 2006), that the VE is a main enabler of agility, reconfiguring organisation dynamically and virtually to react to changing markets effectively. Correct coordination and integration among 
independent enterprises in VE highly supports ASC. Second, the result supports that external changes have a positive impact on ASC. This finding consists with prior studies (Yusuf et al., 2004; Vázquez-Bustelo et al., 2007; Zhang and Sharifi, 2007; Tseng and Lin, 2011). Current study has proven empirically how external changes drive agility in complex systems. Third, the result indicates that ICT adoption has a negative impact on ASC. However this finding is not consistent with prior studies of Ngai et al., (2011), DeGroote and Marx (2013), Liu et al. (2013) etc., who showed the ICT adoption has a stronger indirect effect on ASC. A possible explanation could be that ICT adoption is impacting on agility through mediating factors such as the VE providing more efficient BP. Continuous ICT adoption is more effective in providing ASC. However, although the study does not prove that there is any direct impact of DCs on the ASC; the indirect effect analysis reveals that DCs have a totally positive effect on the ASC. This means that an improvement in DCs affect the achievement of the ASC more efficiently through the right strategy over a long period of time comparing to a short period of time.

The survey result demonstrates that the ASC has a strong and positive impact on the BP. This result consists with previous studies (Swafford et al., 2008; Liu et al., 2013; DeGroote and Marx, 2013). On the other hand, VE affiliation has a strong indirect effect on BP. The BP measures the efficiency and effectiveness of actions such as providing agility capability using the VE strategy within SC. The study verifies that VE is an important strategy in achieving ASC to provide efficient BP. Thus from the RBV perspective, the results have highlighted to enterprises to select the informal and dynamic strategy of forming VE to make valuable, rare and inimitable network resource like agility and sustain the competitive advantages.

\section{Conclusion}

To fulfil the research aims, driving and enabling factors and outcome from the relationship between VE and agility were identified and hypotheses were developed based on literature review, and an empirical study was conducted to test the hypotheses and to provide insights for practitioners and researchers alike. Several important findings emerged from the research have both theoretical and managerial contributions.

This study made following major theoretical contributions. First, the study bridged separate studies on SCC, VE, and ASC by applying the RBV, and developed an aggregated research schema. The research theory is grounded in the overlapping area of three main theoretical concepts of SCC, VE and ASC. In the proposed aggregated research schema, collaboration in SC is assumed as a base that built trust and feed enterprises to join together within short period to exploit fast changing business opportunities. As a temporary alliance VE is perceived as an implementing strategy for enterprises that is not simultaneously being implemented by other potential competitors thus sustains the competitive advantages. Agility is interpreted as a rare, valuable, imperfectly imitable and non-substitutable network resource, and it could become heterogeneous and immobile with support of strategy to join in VE. BP measures the output of strategy and effectiveness of heterogeneous and immobile networks resource.

Second, the proposed conceptual model demonstrates and hypothesizes the relationship between VE and ASC in complex systems with drivers, enablers, capability and outcome. The conceptual model has a purpose to investigate how external and internal drivers influence on achievement of agility through VE, and how ICT 
adoption and VE leverage agility to provide better BP in SC. However, limited studies have examined the relation between VE and agility simultaneously, hypotheses were proposed and a survey based on a structured questionnaire was processed and distributed among Mongolian logistics companies who have active export and import and web utilization.

Third, rich empirical evidence was provided by this study that supports the research hypotheses, enriches understanding of relation between VE and agility in complex and give insights for managers. Whereas, findings suggest to managers that through selecting the informal strategy of joining in VE in ever-changing environment could achieve more ASC and BP, the partners' DCs are most important factor to form the VE.

Furthermore, this study has some practical implications for managers. Resource based approach considers, the set of resource of alliance partners rather than single firm. To exploit owning resource advantages and create competitive advantages in recent changing marketplace, firms have developed many collaborating strategies to address partners within SC to receive relational rent. To sustain the competitive advantage, firm need to consider the informal and emerging strategies like forming temporary alliance to exploit business opportunities and make network resource heterogeneous and immobile. Joining VE could be one of proper strategies nowadays, that enables ASC and provide better BP. Achieved agility could be a network resource that made by temporary alliance formation and rare, valuable, imperfectly imitable and non-substitute as a source of sustained competitive advantage.

Empirical findings suggest to managers, the ability to integrate, build and reconfigure competences and resources is main factor when implementing to form VE. However this study indicates the DCs do not influence agility directly, strongly effect indirectly. Thus, while managers investigate possibilities to exploit business opportunities and focus on the adoption of ICT, they need to improve their DCs to be selected in VE formation to provide more capabilities and to receive relational rent.

There are some limitations to this study. First, the sample size is still small, which could have an effect on indices of popular fit. An extension of the research (i.e. more questionnaires being collected) may improve the results of the analysis. Also another analysing technique could be adopted to analyse the hypotheses. As the concept of the relationship between VE and ASC is complex and is influenced by many factors, its entire domain cannot be covered in a single study. Future research can expand the conceptual model by considering additional factors and their relationships. Also more alternative models, for instance nested models, can be produced and compared with each other to further verify the hypothetical model. Furthermore, while the sample consisted of Mongolian enterprises, it might be better to collect data from other countries or specific industries that are mostly used in case studies for research on VE or ASC.

\section{Acknowledgment}

This work has been supported by the European Erasmus-Mundus Sustainable eTourism project.

Appendix A: Factor loadings and its reliability for constructs

\begin{tabular}{|c|c|c|c|}
\hline Factors/ Constructs / Items & Mean $\quad$ S.D $^{\mathrm{a}}$ & $\begin{array}{l}\text { Factor } \\
\text { loading }\end{array}$ & $\begin{array}{l}\text { Cronbach's } \\
\text { alpha }\end{array}$ \\
\hline \multicolumn{4}{|l|}{ External changes $(K M O=0.755)$} \\
\hline Changes in marketplace (EX_A) & & & \\
\hline
\end{tabular}


EX_A1 Decreasing new products time to market

EX_A2 Product lifetime shrinkage

EX_A3 Increasing rate of change in product models

Changes in competition (EX_B)

EX_B2 New initiatives of competitors

EX_B3 Competitors technological advance

EX_B4 Increasing pressure on cost

Changes in customer requirements (EX_C)

EX_C1 Quality increasing and price decreasing expectation

EX_C2 Quicker delivery time and time to market

EX_C3 Advanced technology in product model

Changes in technology and innovation (EX_D)

EX_D1 Time decreases on introduction of new soft technologies (software and methods)

EX_D2 Time decreases on introduction of new innovation

$D C(K M O=0.915)$

Strategy and human related competency (DC_AE)

DC_A2 Manager's skills to make quick and perfect decision

DC_A3 Employees' skills and knowledge to use new technology

DC_E1 Sensing/identifying changes and fast response

DC_E2 Fast operation time

Information quality (DC_B)

DC_B1 Information accuracy

DC_B2 Information availability

DC_B3 Real-time information

DC_B4 Frequency for updating information

DC_B5 Information accessibility

Technology competency (DC_C)

DC_C1 Usage percentage of new technologies for operations

DC_C3 Frequency to update technology

DC_C4 Level of automation in operations

DC_C5 Technological innovation in product and process

System integration competency (DC_D)

DC_D1 Integration of operation system

DC_D2 Hole internal system integration

DC_D3 Integration of internal and external connectivity

ICT adoption $(K M O=0.879)$

IS (ICT_A)

ICT_A1 Supplier relationship management

ICT_A2 Production IS

ICT_A3 Finance IS

ICT_A4 Advanced ISs to track and/or expedite shipments

ICT_A5 Customer relationship management

ICT_A6 Usage of own web

ICT_A7 Integration of IS

Usage of information technology (ICT_B)

ICT_B1 PC usage and capability to connect internet

ICT_B3 Other devices (e.g.. scanners. Printers, pocket PC)

ICT_B4 Internal and external communication network

Smart technology (ICT_C)

$\begin{array}{llll}2.927 & 0.995 & 0.693 & 0.733 \\ 2.833 & 0.976 & 0.831 & \\ 3.308 & 1.077 & 0.782 & \\ & & & \\ 3.469 & 1.072 & 0.847 & 0.774 \\ 3.590 & 1.065 & 0.803 & \\ 3.590 & 1.145 & 0.774 & \\ & & & \\ 3.203 & 1.135 & 0.797 & 0.674 \\ 3.115 & 1.016 & 0.771 & \\ 3.402 & 1.033 & 0.649 & \\ & & & \\ 2.957 & 0.871 & 0.894 & 0.871 \\ 2.947 & 0.864 & 0.901 & \end{array}$

3.737

3.859

3.537

3.226

3.532

$0.937 \quad 0.786$

0.919

3.566

3.576

3.532

3.444

$0.930 \quad 0.828$

$0.902 \quad 0.819$

$0.998 \quad 0.679$

$0.898 \quad 0.663$

$\begin{array}{lll}3.517 & 0.932 & 0.743\end{array}$

0.893

$\begin{array}{lll}3.260 & 0.998 \quad 0.872\end{array}$

$3.361 \quad 1.046 \quad 0.720$

$\begin{array}{lll}3.309 & 0.989 & 0.732\end{array}$

3.541

0.877

0.661

0.865

3.644

$0.993 \quad 0.842$

3.556

$0.956 \quad 0.801$

3.431

1.057

0.757

0.905

$\begin{array}{lll}3.399 & 0.987 & 0.711\end{array}$

$3.780 \quad 1.027 \quad 0.774$

$\begin{array}{lll}3.385 & 1.077 \quad 0.800\end{array}$

$\begin{array}{lll}3.673 & 0.998 & 0.765\end{array}$

$\begin{array}{lll}3.761 & 1.079 & 0.644\end{array}$

$\begin{array}{lll}3.561 & 1.113 & 0.710\end{array}$

$\begin{array}{lll}4.337 & 0.923 \quad 0.892\end{array}$

0.834

$\begin{array}{lll}4.385 & 0.836 & 0.878\end{array}$

$\begin{array}{lll}3.882 & 1.022 \quad 0.701\end{array}$

0.809

\section{4}

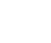

\section{4}

871 
DSS (ICT_D)

ICT_D1 Intelligent Agent application for data and information processing

ICT_D2 Analyze basic data and information (factors, numbers, and characteristics)

$2.569 \quad 1.149 \quad 0.891$

ICT_D3 Model analyze of factors, numbers, and characteristics with user criteria

$2.554 \quad 1.093 \quad 0.884$

ICT_D4 Make decision itself and interface to user

$2.619 \quad 1.106 \quad 0.847$

Virtual enterprise $(K M O=0.880)$

Ability to share business opportunity (VE_A)

VE_A2 Actively share intellectual property (technology and innovation) with partners

VE_A3 Concurrent execution of activities throughout the SC

VE_A4 Share resources (human, technology, information and finance)

Ability to affiliate or organize the VE and to share information and knowledge (VE_BD)

VE_B3 Ability to make right decision quickly

VE_B4 Ability to choose right partner quickly

VE_D1 Information sharing with supplier is timely, accurate, complete, adequate \& reliable

VE_D2 Information sharing with customer is timely, accurate, complete, adequate \& reliable

VE_C3 Financial flow risk (exchange rate risk, price and cost risk, financial strength of SC

VE_C4 Material flow risk (sourcing flexibility risk, supply product monitoring/ quality, SC capacity, product and process design risk, operational disruption, demand volatility/ seasonality, balance of unmet demand and excess inventory)

VE_C5 Transportation disruption (accident, transportation union strike, etc.)

VE_C6 Man-made disasters (e.g. terrorism and political instability)

VE_C7 Natural hazard (e.g. earthquakes, storms, floods, fires, diseases)

VE_C8 Insurance consumption Time and cost reduction (VE_E)

VE_E4 Manufacturing or distributing time reduction

VE_E7 Outbound logistics cost reduction

Prevent, detect, respond and recover from a contamination/security event in VE (VE_F)

VE_F1 Information sharing security process management

VE_F2 Partner security management

VE_F3 Service provider security management

Responsiveness and competency (ASC_AB)

ASC_A1 Fast response to changing market requirements

ASC_A2 Fast response to changing competitors activities

ASC_A3 Quick and right decision making capability

ASC_A4 Create appropriate and right information and communication

ASC_B1 Skill and knowledge enhancement

ASC_B2 Appropriate ICT and smart technology usage 


\begin{tabular}{lllll} 
ASC_C2 & Adjustment of worldwide delivery capacity/ capability & 3.639 & 0.937 & 0.776 \\
ASC_C3 & Flexibility/ adaptability in payment & 3.712 & 0.950 & 0.801 \\
ASC_C4 & Level of customization & 3.639 & 0.983 & 0.712 \\
Quickness/ speed and quality (ASC_DE) & & & 0.72 & 0.919 \\
ASC_D3 & Reduction of supply time & 3.473 & 0.872 & 0.702 \\
ASC_D4 & Reduction of manufacturing time & 3.391 & 0.934 & 0.707 \\
ASC_D5 & Reduction of distributing time & 3.488 & 0.831 & 0.743 \\
ASC_E1 & Product and service quality & 3.293 & 0.830 & 0.736 \\
ASC_E2 & Producing performance quality & 3.332 & 0.827 & 0.847 \\
ASC_E3 & Information sharing quality & 3.325 & 0.769 & 0.803 \\
ASC_E4 & Decision making quality & 3.327 & 0.802 & 0.851 \\
BP(KMO & O.902) & & & 0.863 \\
BP_A1 & Customer satisfaction & 4.029 & 0.766 & 0.916 \\
BP_A2 & Quality improvement & 3.902 & 0.817 & 0.864 \\
BP_A3 & Cost minimization & 3.546 & 0.936 & 0.778 \\
BP_A4 & Delivery speed & 3.808 & 0.850 & 0.812 \\
BP_A5 & New product introduction & 3.764 & 0.904 & 0.783 \\
BP_A6 & Service level improvement & 3.995 & 0.783 & 0.874 \\
BP_A7 & Lead time reduction & 3.902 & 0.897 & 0.759 \\
\hline PS_Dis & & & &
\end{tabular}

${ }^{a}$ S.D is standard deviation, shows how much variation or dispersion exists from the mean.

\section{References}

Aerts, A.T.M., Szirbik, N.B., \& Goossenaerts, J.B.M. (2002). A flexible, agent-based ICT architecture for virtual enterprises. Computers in Industry, 49, 311-327.

Agarwal, A., Shankar, R., \& Tiwari, M.K. (2007). Modeling agility of supply chain. Industrial Marketing Management, 36, 443-457.

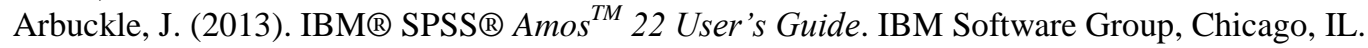

Armstrong, J.S., \& Overton, T.S. (1977). Estimating Nonresponse Bias in Mail Surveys. Journal of Marketing Research, $14,396-402$.

Barney, J. (1991). Firm Resources and Sustained Competitive Advantage. Journal of management, 17, 99-120.

Binder, M., \& Clegg, B. (2007). Enterprise management: A new frontier for organisations. International Journal of Production Economics, 106, 409-430.

Braunscheidel, M.J., \& Suresh, N.C. (2009). The organizational antecedents of a firm's supply chain agility for risk mitigation and response. Journal of Operations Management, 27, 119-140.

Business Insider (2011). The 11 " $3 G$ " Countries That Will Win The Future.

Byrne, J., Brandt, R., Port, O. (1993). The virtual corporation. Week February 8, 98-102.

Camarinha-Matos, L.M., Afsarmanesh, H., \& Galeano, N., Molina, A. (2009). Collaborative networked organizations Concepts and practice in manufacturing enterprises. Computers \& Industrial Engineering, 57, 46-60.

Cao, M., \& Zhang, Q. (2011). Supply chain collaboration: Impact on collaborative advantage and firm performance. Journal of Operations Management, 29, 163-180.

Cao, Q., \& Dowlatshahi, S. (2005). The impact of alignment between virtual enterprise and information technology on business performance in an agile manufacturing environment. Journal of Operations Management, 23, 531-550.

Christopher, M. (2000). The Agile Supply Chain: Competing in Volatile Markets. Industrial Marketing Management, 29, 37-44.

Cruz-Cunha, M.M., \& Putnik, G.D. (2006). Agile Virtual Enterprises: Implementation and Management Support. IGI Global.

Davidow, W.H., \& Malone, M.S. (1993). The Virtual Corporation: Structuring and Revitalizing the Corporation for the $21^{\text {st }}$ Century. Harper Business.

DeGroote, S.E., \& Marx, T.G. (2013). The impact of IT on supply chain agility and firm performance: An empirical investigation. International Journal of Information Management, 33, 909-916.

Dyer, J.H., \& Singh, H. (1998). The Relational View: Cooperative Strategy and Sources of Inter organizational Competitive Advantage. Academy of Management Review, 23, 660-679.

Esposito, E., \& Evangelista, P. (2014). Investigating virtual enterprise models: literature review and empirical findings. International Journal of Production Economics, 148, 145-157.

Fisher, R.A. (1970). Statistical methods for research workers, 14th ed., revised and enlarged. ed. Oliver and Boyd, Edinburgh. 
Gulati, R. (1999). Network location and learning: the influence of network resources and firm capabilities on alliance formation. Strategic Management Journal, 20, 397-420.

Gunasekaran, A., Lai, K., \& Edwincheng, T. (2008). Responsive supply chain: A competitive strategy in a networked economy. Omega, 36, 549-564.

Gunasekaran, A., \& Yusuf, Y.Y. (2002). Agile manufacturing: A taxonomy of strategic and technological imperatives. International Journal of Production Research, 40, 1357-1385.

Hair, J.F., Black, W.C., Babin, B.J., \& Anderson, R.E. (2010). Multivariate data analysis, $7^{\text {th }}$ ed. Prentice Hall, Upper Saddle River, NJ.

IBM Corporation (2011). IBM SPSS Statistics for Windows, Version 20. ed. IBM Corporation, Armonk, NY.

Ismail, H.S., \& Sharifi, H. (2006). A balanced approach to building agile supply chains. International Journal of Physical Distribution \& Logistics Management, 36, 431-444.

Kaiser, H.F. (1974). An index of factorial simplicity. Psychometrika 39, 31-36.

Katzy, B.R., Loeh, H., \& Zhang, C. (2004). Virtual Organising Scenarios, in: Camarinha-Matos, L.M., Afsarmanesh, H. (Eds.), Collaborative Networked Organizations. Kluwer Academic Publishers, Boston, pp. 27-40.

Kidd, P.T. (1994). Agile manufacturing: Forging new frontiers, Addison-Wesley series in manufacturing systems. Addison-Wesley, Wokingham, England; Reading, Mass.

Kline, R.B. (2011). Principles and Practice of Structural Equation Modeling. Guilford Press.

Koçoğlu, İ., İmamoğlu, S.Z., İnce, H., \& Keskin, H. (2011). The effect of supply chain integration on information sharing:Enhancing the supply chain performance. Procedia-Social and Behavioral Sciences, 24, 1630-1649.

Kumar, G., \& Nath Banerjee, R. (2014). Supply chain collaboration index: an instrument to measure the depth of collaboration. Benchmarking International Journal, 21, 184-204.

Lavie, D. (2006). The Competitive Advantage of Interconnected Firms: An Extension of the Resource-Based View. Academy of Management Review, 31, 638-658.

Leonard-Barton, D. (1992). Core capabilities and core rigidities: A paradox in managing new product development. Strategic Management Journal, 13, 111-125.

Liao, S.-H., \& Kuo, F.-I. (2014). The study of relationships between the collaboration for supply chain, supply chain capabilities and firm performance: A case of the Taiwan's TFT-LCD industry. International Journal of Production Economics, 156, 295-304.

Liu, H., Ke, W., Wei, K.K., \& Hua, Z. (2013). The impact of IT capabilities on firm performance: The mediating roles of absorptive capacity and supply chain agility. Decision Support Systems, 54, 1452-1462.

Nagal, R., \& Dove, R. (1991). 21st century manufacturing enterprise strategy: an industry-led view. Iacocca Institute, Lehigh University.

Naylor, B.J., Naim, M.M., \& Berry, D. (1999). Leagility: Integrating the lean and agile manufacturing paradigms in the total supply chain. International Journal of Production Economics, 62, 107-118.

Ngai, E.W.T., Chau, D.C.K., \& Chan, T.L.A. (2011). Information technology, operational, and management competencies for supply chain agility: Findings from case studies. The Journal of Strategic Information Systems, 20 , 232-249.

Ramanathan, U., \& Gunasekaran, A. (2014). Supply chain collaboration: Impact of success in long-term partnerships. Building Supply Chain System Capabilities in the Age of Global Complexity: Emerging Theories and Practices. International Journal of Production Economics, 147, Part B, 252-259.

Ramanathan, U., \& Muyldermans (2011). Identifying the underlying structure of demand during promotions: A structural equation modelling approach. Expert Systems with Applications, 38(5), 5544-5552.

Rezgui, Y. (2007). Role-based service-oriented implementation of a virtual enterprise: A case study in the construction sector. Computers in Industry, 58, 74-86.

Rodríguez Monroy, C., \& Vilana Arto, J.R. (2010). Analysis of global manufacturing virtual networks in the aeronautical industry. International Journal of Production Economics, 126, 314-323.

Sarkis, J. (2001). Benchmarking for agility. Benchmarking International Journal, 8, 88-107.

Soosay, C.A., Hyland, P.W., \& Ferrer, M. (2008). Supply chain collaboration: capabilities for continuous innovation. Supply Chain Management, An International Journal, 13, 160-169.

Subramanian, N., Gunasekaran A., Yu J., Cheng J., \& Ning K. (2014). Customer satisfaction and competitiveness in the Chinese E-retailing: Structural equation modeling (SEM) approach to identify the role of quality factors. Expert Systems with Applications. 41(1), 69-80.

Swafford, P.M., Ghosh, S., \& Murthy, N. (2008). Achieving supply chain agility through IT integration and flexibility. International Journal of Production Economics, 116, 288-297.

Teece, D.J., Pisano, G., \& Shuen, A. (1997). Dynamic capabilities and strategic management. Strategic Management Journal, 18, 509-533.

Tseng, Y.H., \& Lin, C.T. (2011). Enhancing enterprise agility by deploying agile drivers, capabilities and providers. Information Sciences, 181, 3693-3708.

Van Hoek, R.I., Harrison, A., \& Christopher, M. (2001). Measuring agile capabilities in the supply chain. International Journal of Operations \& Production Management, 21, 126-148. 
Vázquez-Bustelo, D., Avella, L., \& Fernández, E. (2007). Agility drivers, enablers and outcomes: Empirical test of an integrated agile manufacturing model. International Journal of Operations \& Production Management, 27, 13031332.

Wang, M., Wang, H., \& Liu, J. (2007). Dynamic Supply Chain Integration through Intelligent Agents. IEEE Transition System Sciences, 46-46.

Yauch, C.A. (2011). Measuring agility as a performance outcome. Journal of Manufacturing Technology Management, 22, 384-404.

Yusuf, Y.., Gunasekaran, A., Adeleye, E., \& Sivayoganathan, K. (2004). Agile supply chain capabilities: Determinants of competitive objectives. European Journal of Operational Research, 159, 379-392.

Zhang, Z., \& Sharifi, H. (2007). Towards theory building in agile manufacturing strategy - A taxonomical approach. IEEE Transition Engineering Management, 54, 351-370. 